\title{
Simultaneous retinal and iris metastases in small cell lung carcinoma
}

\begin{abstract}
Purpose: The aim of this study is to present the case of a 60 -year-old male with a rare presentation of small cell lung carcinoma (SCLC) metastases to the retina and iris.

Methods: The patient's history and ophthalmic examinations, including best corrected visual acuity, intraocular pressure, slit-lamp biomicroscopy, fundoscopy, spectral-domain optical coherence tomography (SD-OCT), fluorescein angiography, and histopathology, are described.

Results: A 60-year-old male was diagnosed with SCLC, with a TNM classification of TxN3M1b. On ophthalmic examination, a greyish-white gelatinous iris mass in the right eye and an ill-defined yellow-white retinal lesion with intrinsic hemorrhages in the left eye were found. SD-OCT through the retinal lesion revealed thickening of the retina and inner retinal replacement by tumor. No apparent involvement of the underlying choroid was noted. Fluorescein angiography revealed a hyperfluorescent mass with intrinsic vascularity in the left eye and the hyperfluorescence increased during the late phase. Excisional biopsy and immunohistochemistry of the iris mass showed the tumor cells were consistent with a metastatic small cell carcinoma.
\end{abstract}

Conclusion: In all ocular metastases, uveal metastasis is the most common form. Metastases to the retina, optic disc, and vitreous are rare. We report an unusual case of a patient with SCLC presented with simultaneous retina and iris metastases in the both eyes. The SD-OCT features of the retinal metastasis from SCLC are presented for the first time.
Volume 8 Issue I - 2018

\author{
Hao-Jung Li, Chih-Heng Hung, Shwu-Huey \\ Lee,Yi-Chun Chen \\ Department of Ophthalmology, Cathay General Hospital,Taiwan
}

Correspondence: Yi-Chun Chen, Department of

Ophthalmology, Cathay General Hospital 280, Section 4, Ren-ai Rd,Taipei, Taiwan, Tel 886-2-27082/2I-8I3I,

Email rebe254cca@gmail.com

Received: December 31, 2017 | Published: January 16, 2018

Keywords: retina metastasis, iris metastasis, small cell lung carcinoma

Abbreviations: SCLC, small cell lung carcinoma; SD-OCT, spectral-domain optical coherence tomography

\section{Introduction}

Metastatic carcinoma is the most common intraocular malignancy in the adult population, and the most common primary cancers are breast cancer, followed by lung cancer. ${ }^{1}$ In all ocular metastases, uveal metastasis is the most common form. The choroid is the most common site for uveal metastasis. ${ }^{2}$ Shah et al., ${ }^{3}$ investigated 194 patients with uveal metastasis from lung cancer and found that the tumor locations included choroid ( $88 \%)$, iris (10\%), and ciliary body ( $2 \%)$. Metastases to the retina, optic disc, and vitreous are rare. ${ }^{4}$ Shields et al., ${ }^{5}$ reported that, there were only 8 patients being diagnosed with retinal metastasis from systemic cancer during a 40-year period at an oncology referral center. Small cell lung carcinoma (SCLC) constitutes $14 \%$ of all lung cancers in the United States. ${ }^{6}$ Its prognosis is significantly worse than non-small cell carcinoma because of the tendency of rapid growth and early and widespread dissemination. We are presenting an unusual case of 60-year-old male with SCLC who developed multiple ocular metastases in the retina and iris. We will highlight the clinical features of histopathology, immunohistochemistry, and spectral-domain optical coherence tomography (SD-OCT) in the ocular metastases from SCLC.

\section{Case presentation}

A 60-year-old male was referred to Cathay General Hospital for the further evaluation of malignancy. Small cell lung carcinoma
(SCLC) was diagnosed with a TNM classification of TxN3M1b. During admission, he complained of having redness and tearing of right eye for one month. On ophthalmic examination, best corrected visual acuity was $0.5 \mathrm{OD}$ and $0.6 \mathrm{OS}$. Intraocular pressure was 16 $\mathrm{mmHg}$ OU. Slit-lamp biomicroscopy revealed a greyish-white gelatinous iris mass located between 8 o'clock to 10 o'clock pupillary margins in the right eye (Figure 1). No abnormality was found in the ocular fundus of right eye. Fundoscopy of the left eye revealed an illdefined yellow-white retinal lesion with intrinsic hemorrhages located in the temporal quadrant (Figure 2). SD-OCT through the lesion suggested thickening of the retina and inner retinal replacement by tumor (Figure 3). No apparent involvement of the underlying choroid was noted. Fluorescein angiography revealed a hyperfluorescent mass with intrinsic vascularity in the left eye and the hyperfluorescence increased during the late phase (Figure 4). Excisional biopsy of the iris mass in the right eye was performed for histopathologic examination. The tumor consisted of several nests of epithelioid neoplastic cells characterized by high nuclear-to-cytoplasmic ratio, scant cytoplasm, nuclear hypercromasia and molding, and salt-and-pepper chromatin pattern. Mitotic figures were numerous. Immunohistochemistry showed tumor cells were positive for cytokeratin AE1/AE3 and synaptophysin (Figure 5). The morphology and immunoprofiles were consistent with a metastatic small cell carcinoma. The patient received chemotherapy and brain radiotherapy. Two months after treatment, multiple iris nodules reappeared in the right eye and the retinal lesion of left eye continued to expand. SD-OCT showed the inner retinal tumor extended to the outer retina six months after treatment. Given the continued deteriorating health and poor systemic prognosis, no 
intervention of the ocular metastases was considered necessary. Approximate eight months after the initial diagnosis, the patient died due to a disseminated SCLC.

A



B

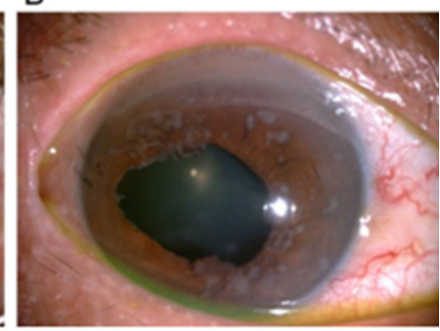

Figure I (A) Photograph at presentation, showing a greyish-white gelatinous iris mass located between 8 o'clock to 10 o'clock pupillary margins in the right eye. (B) Two months after excision, chemotherapy, and radiotherapy, multiple iris nodules reappeared.

\section{A}
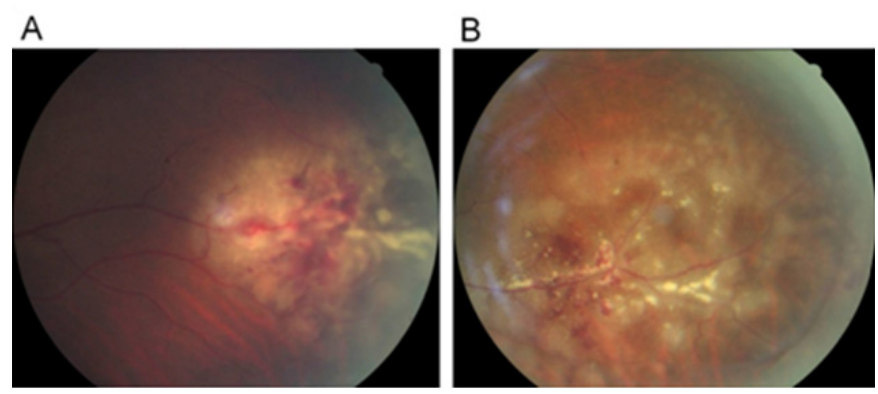

Figure 2 (A) Fundus photograph at presentation, showing an ill-defined yellow-white retinal lesion with intrinsic hemorrhages in the left eye. (B) Two months after chemotherapy and radiotherapy, the extent of retinal lesion expanded.

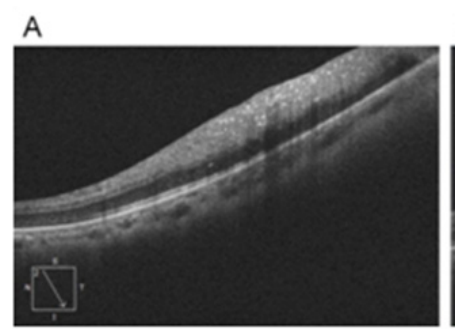

B

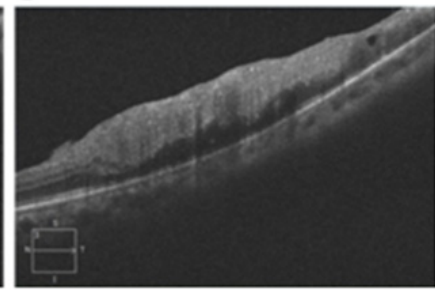

Figure 3 (A) Spectral-domain optical coherence tomography at presentation, showing thickening of the retina and inner retinal replacement by tumor in the left eye. The choroid was apparently unremarkable. (B) Six months after chemotherapy and radiotherapy, the inner retinal tumor extended to the outer retina.

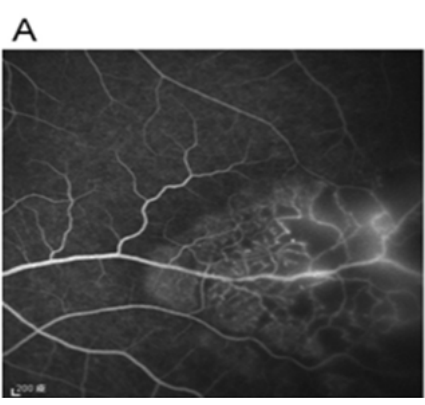

B

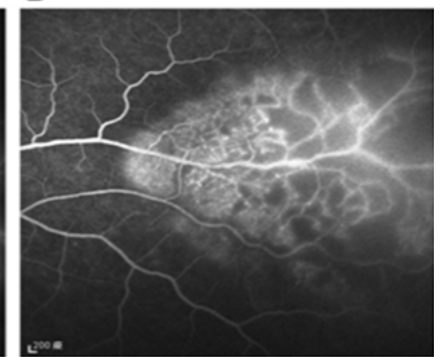

Figure 4 (A) Fluorescein angiography at presentation, showing a hyper fluorescent mass with intrinsic vascularity in the left eye. (B) The hyper fluorescence increased during the late phase.
A

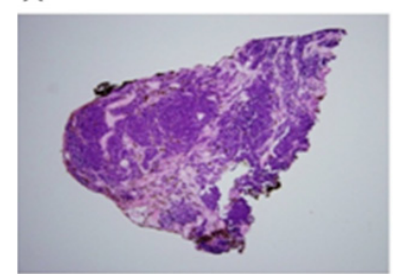

C

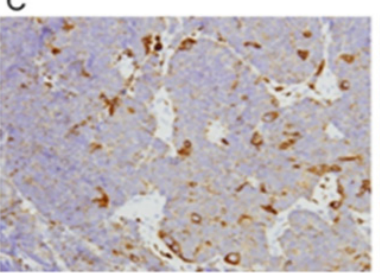

B

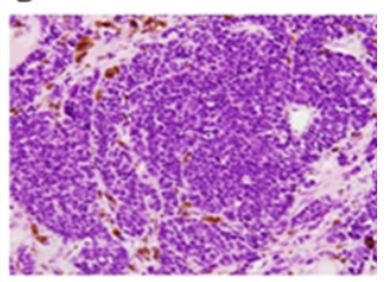

D

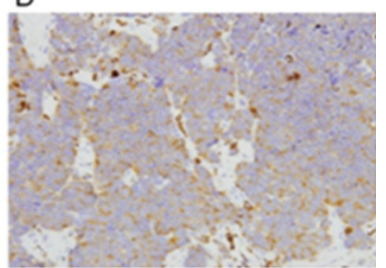

Figure 5 (A) Several nests of epithelioid neoplastic cells undermining the whole iris layers. (H\&E stain, $\times 10)(B)$ Tumor cells with nuclear hyperchromasia and numerous mitotic figures. (H\&E stain, $\times 40)(C, D)$ Positive immune histochemical staining of cytokeratin AEI/AE3 and synaptophysin, $\times 40$.

\section{Discussion}

$\mathrm{Xu}$ et al., ${ }^{7}$ reported that the most common lung cancer that metastasizes to the eye was adenocarcinoma. Adenocarcinoma constituted $47.6 \%$ and SCLC constituted $21.4 \%$. Shah et al. ${ }^{3}$ found that in patients with uveal metastasis from lung cancer, the primary lung cancer included non-small cell lung cancer (84\%) and SCLC $(16 \%)$. They also revealed that only $18 \%$ of patients were shown to have involvement in the both eyes. The choroid is the most common site for ocular metastasis from lung cancer. ${ }^{3,7}$ The most common site of ocular metastases from SCLC is iris. ${ }^{8-16}$ One case of choroidal metastasis from SCLC was found. ${ }^{17}$ Only one patient with retinal metastasis from SCLC has been reported. Simunovic et al., ${ }^{18}$ reported a 65-year-old female with SCLC presented with unilateral ocular metastasis involving retina. We have reported an unusual case of a patient with SCLC presented with simultaneous retina and iris metastases in the both eyes. The SD-OCT features of the retinal metastasis from SCLC were presented for the first time and SD-OCT may aid in the diagnosis and monitoring of the retinal metastasis. Due to tumor cells entering the eye through a haematogenous route, diffuse systemic dissemination of tumor cells through the same route would be presumed. Thus retinal metastasis is generally considered as a poor prognostic sign for the long-term survival. ${ }^{5}$ As the systemic prognosis of a SCLC patient with retinal metastasis is poor, systemic treatments are preferred, like our patient. The treatment strategy for ocular metastases may be observation unless sequelae such as neovascular glaucoma happen.

\section{Conclusion}

Simultaneous retinal and iris metastases from SCLC are very rare and can be considered as a sign of poor systemic prognosis.

\section{Acknowledgments}

None.

\section{Funding}

None. 


\section{Conflicts of interest}

Author declares that there are no conflicts of interest.

\section{References}

1. Shields CL, Shields JA, Gross NE, et al. Survey of 520 eyes with uveal metastases. Ophthalmology. 1997;104(8):1265-1276.

2. Arepalli S, Kaliki S, Shields CL. Choroidal metastases: Origin, features, and therapy. Indian J Ophthalmol. 2015;63(2):122-127.

3. Shah SU, Mashayekhi A, Shields CL, et al. Uveal metastasis from lung cancer: clinical features, treatment, and outcome in 194 patients. Ophthalmology. 2014;121(1):352-357.

4. De Potter P. Ocular manifestations of cancer. Curr Opin Ophthalmol. 1998;9(6):100-104.

5. Shields CL, McMahon JF, Atalay HT, et al. Retinal metastasis from systemic cancer in 8 cases. JAMA Ophthalmol. 2014;132(11):1303-1308.

6. Travis WD. Update on small cell carcinoma and its differentiation from squamous cell carcinoma and other non-small cell carcinomas. Mod Pathol. 2012;25(Suppl 1):S18-S30.

7. Xu Y, Sun Y, Zhao J, et al. Ocular metastasis in lung cancer: a retrospective analysis in a single Chinese hospital and literature review. Zhongguo Fei Ai Za Zhiy. 2017;20(5):326-333.

8. Moura LR, Yang YF, Ayres B, et al. Clinical, histologic, and immunohistochemical evaluation of iris metastases from small cell lung carcinoma. Can J Ophthalmol. 2006;41(6):775-777.
9. Roenhorst AW, van den Bergh AC, van Putten JW, et al. Iris metastasis in small-cell lung carcinoma. J Thorac Oncol. 2007;2(12):1128-1129.

10. Nakashima C, Keino H, Watanabe T, et al. Intravitreal bevacizumab for iris metastasis of small-cell lung carcinoma with neovascular glaucoma. Jpn J Ophthalmol. 2011;55(1):80-81.

11. Fukui S, Takagi Y, Ozaki N, et al. Asymptomatic iris metastasis of smallcell lung cancer. Int Canc Conf J. 2012;1(3):138-141.

12. Nikratowicz D, Rospond-Kubiak I, Kocięcki J. Small-cell lung carcinoma metastasis to the iris-case presentation. Contemp Oncol. 2013;17(3):331333.

13. Hata M, Inoue T. Iris metastasis from small-cell lung cancer. J Thorac Oncol. 2014;9(10):1584-1585.

14. Karunanithi S, Sharma $\mathrm{P}$, Jain $\mathrm{S}$, et al. Iris metastasis in a patient with small cell lung cancer: incidental detection with 18F-FDG PET/CT. Clin Nucl Med. 2014;39(6):554-555.

15. Sakellakis M, Peroukides S, Iconomou G, et al. Iris metastasis in a patient with small cell lung cancer: a case report. Iran Red Crescent Med J. 2016;18(4):e21522.

16. Liu SL, Nie YH, He T, et al. Iris metastasis as the first sign of small cell lung cancer: a case report. Oncol Lett. 2017;13(3):1547-1552.

17. Lim HH, Choi SY, Yoo HJ, et al. Choroidal metastasis of small cell lung cancer. J Thorac Oncol. 2006;1(7):714-715.

18. Simunovic MP, Thaung C, da Cruz L, et al. Small cell carcinoma of the lung metastatic to the retina: a clinicopathologic case report. Can J Ophthalmol. 2015;50(6):e119-e121. 